\title{
EFEITO DE RECIPIENTES E SUBSTRATOS UTILIZADOS NA PRODUČ̃̃ DE MUDAS DE CAFEEIRO NO DESENVOLVIMENTO INICIAL EM CASA DE VEGETAÇÃO, SOB ESTRESSE HÍDRICO ${ }^{1}$
}

\author{
Effect of different recipients and substrata used in the production of coffee tree \\ seedlings in the initial development in greenhouse under water stress
}

\author{
Haroldo Silva Vallone ${ }^{2}$, Rubens José Guimarães ${ }^{3}$, Antônio Nazareno Guimarães Mendes ${ }^{3}$, \\ Rodrigo Luz da Cunha ${ }^{4}$, Gladyston Rodrigues Carvalho ${ }^{4}$, Fábio Pereira Dias ${ }^{5}$
}

\begin{abstract}
RESUMO
Com o objetivo de avaliar os efeitos de recipientes e substratos no desenvolvimento inicial de cafeeiros (Coffea arabica L.) plantados em vasos dentro de casa de vegetação, sob diferentes níveis de estresse hídrico, foi conduzido um experimento no Setor de Cafeicultura da Universidade Federal de Lavras - UFLA, no período de janeiro a maio de 2004. O delineamento experimental utilizado foi em blocos casualizados (DBC) em esquema fatorial $(3 \times 3 \times 4)$, sendo o primeiro fator constituído de três recipientes utilizados na produção das mudas, tubetes de polietileno rígido de $50 \mathrm{~mL}$; tubetes de $120 \mathrm{~mL}$; e saquinhos de polietileno, nas dimensões de $20 \mathrm{~cm}$ de altura por $10 \mathrm{~cm}$ de largura e capacidade volumétrica, aproximada, de $700 \mathrm{~mL}$; o segundo fator constituído de três substratos utilizados na produção das mudas, substrato alternativo, composto por $65 \%$ de casca de arroz carbonizada $+35 \%$ de substrato comercial; substrato comercial Plantmax hortaliças HT; e substrato padrão, composto por $70 \%$ de terra $+30 \%$ de esterco bovino peneirados e o terceiro fator foi constituído por quatro intervalos entre irrigações, 2, 6, 10 e 14 dias. Observa-se que os recipientes de capacidades volumétricas diferentes e os substratos utilizados influenciam, significativamente, o desenvolvimento dos cafeeiros, sendo que, após 120 dias do transplante das mudas para vasos em casa de vegetação com diferentes níveis de estresse hídrico, as plantas provenientes de mudas produzidas em saquinhos de polietileno e tubetes de $120 \mathrm{~mL}$ contendo substratos alternativo e comercial apresentaram melhor desenvolvimento.
\end{abstract}

Termos para indexação: Coffea arabica, vasos, tubete, sacola de polietileno.

\begin{abstract}
With the aim of evaluating the effects of different recipients and substrata in the production of coffee tree seedlings (Coffea arabica L.), planted in pots inside the greenhouse, under different water stress levels, an experiment was carried out in the Section of Coffee of Department of Agriculture of Universidade Federal de Lavras - UFLA, in the period from September of 2003 to January of 2004. The experimental outline used was randomized blocks (DBC) in a 3 x 3 factorial arrangement. The recipients used were rigid polyethylene tube with a capacity of $50 \mathrm{~mL} ; 120 \mathrm{~mL}$ tubes; and $20 \mathrm{~cm}$-high, $10 \mathrm{~cm}$-wide polyethylene sacks, with an approximate capacity of $700 \mathrm{~mL}$. The second factor consisted of three substrata used for seedling production: an alternative substratum, composed of $65 \%$ of charred rice peel $+35 \%$ of commercial substratum; the commercial substratum, Plantmax vegetables HT; and the standard substratum, composed of $70 \%$ of earth $+30 \%$ of bovine drizzled manure. The third factor consisted of four intervals $(2,6$, 10 and 14 days) between irrigations The results obtained allow concluding that the recipients and the substrata used significantly influenced the development of the coffee trees. 120 days after the transplantation of the seedlings to pots in the greenhouse with different levels of water stress, we could conclude that larger recipients (polyethylene sack and $120 \mathrm{~mL}$ tube) filled with alternative and commercial substrata provided better seedling development.
\end{abstract}

Index terms: Coffea arabica, pots, tube, sacks of polyethylene.

(Recebido em 5 de junho de 2006 e aprovado em 24 de junho de 2009)

\section{INTRODUÇÃO}

O desenvolvimento inicial de culturas perenes como o cafeeiro, sofre influências de vários fatores, como climáticos, nutricionais e também aqueles ligados à qualidade das mudas utilizadas. Com relação à qualidade das mudas, poucos estudos têm contemplado os efeitos de recipientes e substratos, utilizados durante a produção destas, no desenvolvimento de cafeeiros após o plantio no local definitivo. A grande maioria dos trabalhos restringe-se a avaliar os efeitos apenas durante a fase de produção de mudas, não fornecendo informações

${ }^{1}$ Parte da tese apresentada à Universidade Federal de Lavras, pelo primeiro autor, para obtenção do grau de doutor em Agronomia, área de concentração Fitotecnia

${ }^{2}$ Instituto Federal de Educação, Ciência e Tecnologia do Triângulo Mineiro Campus Uberaba, MG - Rua João Batista Ribeiro, n. 4000 - Mercês - 38.064-790 Uberaba, MG - haroldo@iftriangulo.edu.br

${ }^{3}$ Universidade Federal de Lavras/UFLA - Departamento de Agricultura/DAG - Lavras, MG

${ }^{4}$ EPAMIG/CTSM - Lavras, MG

${ }^{5}$ Instituto Federal de Educação, Ciência e Tecnologia de Minas Gerais Campus Bambuí - Bambuí, MG 
importantes aos cafeicultores que desejam implantar uma lavoura.

Os recipientes mais utilizados para a produção de mudas de cafeeiros são os saquinhos de polietileno e tubetes de polietileno rígido, com capacidade volumétrica inferior à dos saquinhos, entre 50 e $500 \mathrm{~mL}$. Os saquinhos de polietileno apresentam dimensões de 9 a $11 \mathrm{~cm}$ de largura, por 18 a $22 \mathrm{~cm}$ de comprimento e são providos de furos na metade inferior para drenagem (Guimarães \& Mendes, 1998). O substrato utilizado na produção de mudas de cafeeiros em saquinhos normalmente é constituído por $70 \%$ de terra $+30 \%$ de esterco bovino e o mais utilizado para produção em tubetes é constituído de casca de Pinus moída, compostada e enriquecida com nutrientes, entretanto, pesquisadores vêm desenvolvendo outras misturas, visando a buscar alternativas melhores ou mais baratas às existentes no mercado.

Observa-se uma tendência em utilizar recipientes de menores capacidades volumétricas visando a reduzir o custo de produção das mudas. Entretanto, Johnson et al. (1996), citados por Samôr et al. (2002), relatam que o pequeno volume dos recipientes proporciona uma condição de estresse a mudas e, nesses casos, tende a ocorrer aumento de alocação de fotoassimilados para as raízes, em detrimento da parte aérea. De acordo com Reis et al. (1989), caso haja restrições ao desenvolvimento radicular, a má formação inicial das raízes pode persistir após o plantio, prejudicando o desenvolvimento das plantas no campo. Conforme Schimidt-Vogt (1984), a influência do recipiente na conformação do sistema radicular é de suma importância, haja vista que o crescimento em espiral das raízes continua na fase de campo, podendo proporcionar uma baixa estabilidade das futuras árvores. Freitas et al. (2005) também ressaltam que a persistência das deformações radiculares após o plantio e o plantio de mudas menores em função da restrição no viveiro podem reduzir ou atrasar, o crescimento das plantas no campo, causando o retardamento da produção esperada.

Entretanto, Falco et al. (1997) avaliaram a resistência ao estresse hídrico de mudas de cafeeiro produzidas em saquinhos plásticos, tubetes de $120 \mathrm{~mL}$ e raiz nua, em vasos e verificaram, após 120 dias, que as médias de massa seca de raízes e parte aérea de mudas produzidas em tubetes foram superiores às de mudas produzidas em saquinhos e com raiz nua. Matiello et al. (2000) estudaram o desenvolvimento de mudas de cafeeiro produzidas em tubetes de $120 \mathrm{~mL}$ e saquinho de polietileno plantadas no campo e em vasos de 20 litros, dentro de casa de vegetação. Em ambiente protegido, os cafeeiros provenientes de mudas produzidas em tubetes apresentaram desenvolvimento inferior ao das mudas produzidas em saquinhos de polietileno.

Diante do exposto, neste trabalho, objetivou-se avaliar os efeitos de diferentes recipientes e substratos utilizados na produção de mudas de cafeeiro, no desenvolvimento inicial destas, quando cultivadas em vasos, sob diferentes níveis de estresse hídrico.

\section{MATERIAL E MÉTODOS}

Este trabalho foi instalado e conduzido no Setor de Cafeicultura do Departamento de Agricultura da Universidade Federal de Lavras - UFLA, localizada no sul do Estado de Minas Gerais. O experimento foi montado e conduzido em casa de vegetação, utilizando-se mudas de cafeeiro da cultivar Acaiá Cerrado, MG-1474, oriundas de semeadura em germinadores e posterior repicagem para os recipientes. $\mathrm{O}$ delineamento experimental utilizado foi em blocos casualizados, em esquema fatorial ( $3 \times 3 \times 4)$, sendo o primeiro fator constituído de três recipientes utilizados na produção das mudas, tubetes de polietileno rígido com capacidade volumétrica de $50 \mathrm{~mL}$; tubetes de $120 \mathrm{~mL}$; e saquinhos de polietileno, nas dimensões de $20 \mathrm{~cm}$ de altura por $10 \mathrm{~cm}$ de largura e capacidade volumétrica aproximada de $700 \mathrm{~mL}$; o segundo fator constituído de três substratos utilizados na produção das mudas, substrato alternativo, composto por $65 \%$ de casca de arroz carbonizada e $35 \%$ de substrato comercial Plantmax ${ }^{\circledR}$ Hortaliça HT; substrato comercial Plantmax ${ }^{\circledR}$ Hortaliça HT; e substrato padrão, composto por $70 \%$ de terra e $30 \%$ de esterco bovino e o terceiro fator foi constituído por quatro intervalos entre irrigações, 2, 6, 10 e 14 dias. Foram utilizadas 4 repetições, totalizando 36 tratamentos e 144 parcelas. Cada parcela foi composta por 2 vasos, com capacidade de 10 litros de solo, com uma planta em cada. A casa de vegetação apresenta ventilação automática e o acionamento é controlado por um termostato que se liga no momento em que a temperatura no interior da casa de vegetação se encontre em $27^{\circ} \mathrm{C}$. No interior da casa de vegetação, existem bancadas metálicas com um metro de altura, onde foram colocados os vasos do experimento. O solo utilizado foi caracterizado como LATOSSOLO VERMELHO distroférrico típico. O solo foi peneirado em peneira com $1,5 \mathrm{~cm}$ de malha. Em seguida encheram-se os vasos com o mesmo peso de solo seco (8 kg), suplementando com adubação fosfatada, de acordo com Guimarães et al. (1999). O passo seguinte foi determinar o peso médio dos vasos quando o solo dos mesmos se encontrava na capacidade de campo. Para isso, efetuou-se uma irrigação farta em uma amostra de 13 vasos, em seguida, foram cobertos com uma lona preta e permaneceram em local sombreado até atingirem peso 
constante. Efetuou-se também o peso médio das mudas, com torrão, provenientes de cada tratamento. Portanto, ao se plantar cada muda em um respectivo vaso, tinha-se o peso médio de cada vaso, na capacidade de campo, e com uma muda plantada. Efetuou-se o plantio e a partir deste momento, a cada 2, 6, 10 e 14 dias, pesavam-se alguns vasos de cada turno de rega, determinando o peso médio destes, com o solo na umidade atual e se procedia a irrigação, visando a voltar o vaso ao peso com o solo úmido. Esse procedimento foi determinado, seguindo as recomendações de Melo et al. (1998). Paralelamente, foram conduzidos quatro vasos de cada turno de rega para controle do aumento de peso das mudas, foram feitas correções dos pesos médios dos vasos, aos 45 e 90 dias, após o plantio.

O experimento foi conduzido durante 120 dias e ao final deste período foram avaliadas as seguintes características: a) altura das plantas; b) diâmetro da base do caule; c) número de nós nos ramos plagiotrópicos; f) área foliar; g) massa seca do sistema radicular e da parte aérea e h) relação massa seca do sistema radicular/massa seca da parte aérea. Realizaram-se as análises de variância dos dados à significância de $5 \%$ e $1 \%$ de probabilidade pelo teste $\mathrm{F}$, utilizando-se o programa computacional 'SISVAR', desenvolvido por Ferreira (2000). Quando diferenças significativas foram detectadas, os fatores qualitativos foram agrupados pelo teste de Scott-Knott, aos níveis de 5\% e $1 \%$ de probabilidade, para os quantitativos foram feitos ajustes de regressão, segundo metodologia recomendada por Banzatto \& Kronka (1995).

\section{RESULTADOS E DISCUSSÃO}

Para as características altura de plantas, número de nós no ramo ortotrópico e número de ramos plagiotrópicos, nenhuma interação significativa foi detectada, indicando que, para estas, os fatores interferem de maneira independente uns dos outros.
Com relação ao diâmetro de caule, não houve efeito dos substratos, quando se utilizou o tubete de 50 $\mathrm{mL}$ de capacidade volumétrica, e nem efeito dos recipientes, quando se utilizou o substrato comercial. Para os demais tratamentos houve influência significativa, sendo que as plantas provenientes de mudas produzidas no recipiente saquinho de polietileno apresentaram média superior às demais, quando se utilizou o substrato alternativo, porém, quando se utilizou o substrato padrão, a média foi semelhante a das plantas provenientes de mudas produzidas em tubete de $120 \mathrm{~mL}$ e superior a das plantas provenientes de mudas produzidas em tubete de $50 \mathrm{~mL}$. Segundo Vallone (2006), as mudas produzidas em substrato padrão, que durante a fase de viveiro apresentaram as menores médias de diâmetro de caule, mostraram uma surpreendente adaptação à nova condição, proporcionando cafeeiros com médias superiores às demais, tanto no recipiente saquinho de polietileno de $700 \mathrm{~mL}$, quanto no tubete de $120 \mathrm{~mL}$ (Tabela 1).

A variável altura de plantas foi influenciada pelo recipiente utilizado, sendo que, ao se aumentar o recipiente para produção da mudas, aumenta-se também a altura dos cafeeiros (Tabela 2). Resultado semelhante aos obtidos por Reis et al. (1989) e Matiello et al. (2000). Entretanto, discrepantes dos obtidos por Falco et al. (1997). Com relação aos substratos, mais uma vez destaca-se o melhor desempenho das plantas provenientes do substrato padrão que apresentaram a melhor média de altura, apenas 120 dias após o transplante para os vasos. Quanto aos turnos de rega, observou-se um efeito quadrático em função do aumento nos intervalos entre irrigações, com destaque para os dois turnos de rega mais frequentes, sendo que o ponto que proporciona a máxima altura foi estimado em 2,133 dias. A partir daí, como já era esperado, houve um decréscimo acelerado da altura de plantas (Figura 1). Esses resultados são semelhantes aos obtidos por Falco et al. (1997).

Tabela 1 - Valores médios ${ }^{1}$ de diâmetro de caule de cafeeiros 120 dias após o transplante, em milímetros, em função de diferentes recipientes e substratos. UFLA, Lavras, MG, 2006.

\begin{tabular}{lrrr}
\hline \multicolumn{1}{c}{ Recipiente } & \multicolumn{4}{c}{ Substratos } \\
\cline { 2 - 4 } & Alternativo & Comercial & Padrão \\
\hline Tubete $50 \mathrm{~mL}$ & $7,703 \mathrm{~b}$ A & 8,128 a A & 8,076 b A \\
Tubete $120 \mathrm{~mL}$ & $8,114 \mathrm{~b}$ B & 8,228 a B & 876 a A \\
Saquinho $-700 \mathrm{~mL}$ & $8,593 \mathrm{a} \mathrm{B}$ & 8,346 a B & 9,187 a A \\
\hline
\end{tabular}

${ }^{1}$ Médias seguidas pela mesma letra minúscula na vertical e maiúscula na horizontal, não diferem entre si, pelo teste de Scott-Knott, ao nível de $5 \%$ de probabilidade. 
Tabela 2 - Valores médios ${ }^{1}$ de Altura de cafeeiros aos 120 dias após o transplante para vasos em casa de vegetação, em função de recipientes e substratos. UFLA, Lavras, MG, 2006.

\begin{tabular}{lccc}
\hline \multicolumn{1}{c}{ Recipiente } & Altura $(\mathrm{cm})$ & Substrato & Altura $(\mathrm{cm})$ \\
\hline Tubete $50 \mathrm{~mL}$ & $64,573 \mathrm{c}$ & Alternativo & $65,620 \mathrm{~b}$ \\
Tubete $120 \mathrm{~mL}$ & $67,760 \mathrm{~b}$ & Comercial & $66,767 \mathrm{~b}$ \\
Saquinho $-700 \mathrm{~mL}$ & $70,152 \mathrm{a}$ & Padrão & $70,099 \mathrm{a}$ \\
\hline
\end{tabular}

${ }^{1}$ Médias seguidas pela mesma letra minúscula na vertical, não diferem entre si, pelo teste de Scott-Knott, ao nível de 5\% de probabilidade.

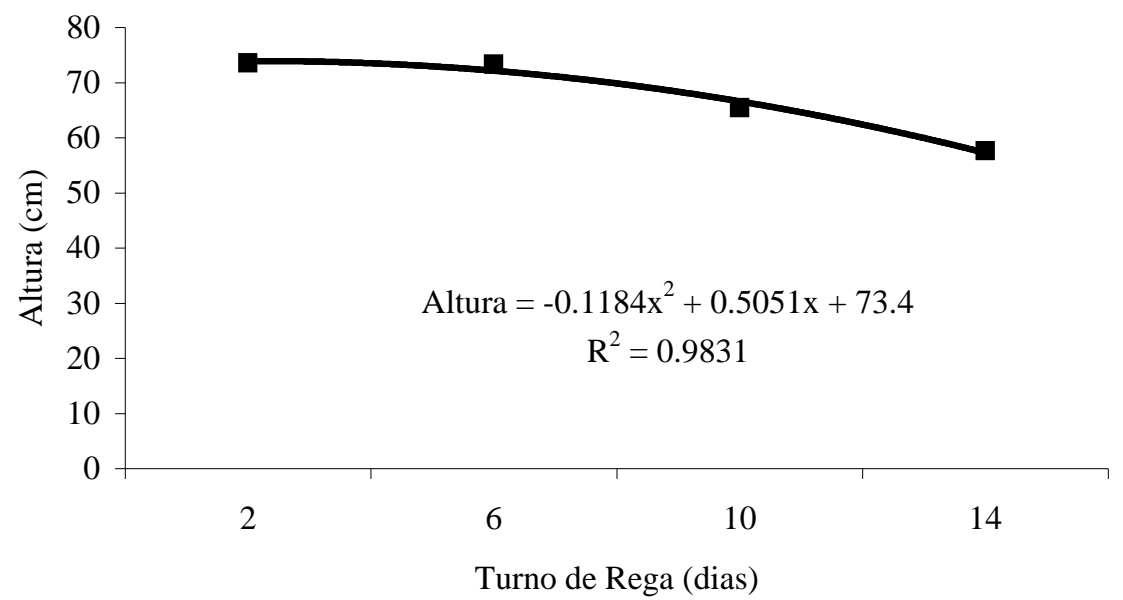

Figura 1 - Altura de cafeeiros aos 120 dias após o plantio, em função do turno de rega. UFLA, Lavras, 2006.

Com relação à área foliar dos cafeeiros, observa-se que, novamente, as mudas produzidas com o substrato padrão apresentaram médias superiores às demais. As médias obtidas em função do substrato utilizado na produção das mudas se encontram na Tabela 3. Foram observados efeitos significativos em função dos turnos de rega de dois, seis e quatorze dias, sendo que as plantas oriundas de mudas produzidas em saquinho de polietileno de $700 \mathrm{~mL}$ apresentaram médias superiores às demais. As plantas oriundas de mudas produzidas em tubete de $50 \mathrm{~mL}$ de capacidade volumétrica apresentaram médias inferiores a todas as demais no turno de rega de dois dias e médias semelhantes às provenientes de mudas produzidas em tubetes de $120 \mathrm{~mL}$ nos demais turnos de rega com efeitos significativos, isto é, 6 e 14 dias (Figura 2).

A característica número de nós nos ramos plagiotrópicos está relacionada diretamente com a capacidade produtiva do cafeeiro, sendo, portanto, de grande importância agronômica. Foram observados efeitos significativos para recipientes, substratos, turno de rega e para a interação recipiente $X$ turno de rega. Na Tabela 3, são apresentados os valores médios observados, 120 dias após o transplante para os vasos. Verifica-se que as plantas provenientes de mudas produzidas com substrato alternativo e comercial apresentaram médias semelhantes e inferiores às obtidas pelas provenientes de mudas produzidas com substrato padrão. Com relação à interação recipiente $\mathrm{X}$ turno de rega, foram observados efeitos significativos de recipientes em todos os turnos de rega aplicados, com destaque para as mudas provenientes do recipiente saquinho de polietileno de $700 \mathrm{~mL}$. As mudas provenientes de tubetes de $50 \mathrm{~mL}$ apresentaram comportamento inferior às demais (Figura 3 ).

A variável massa seca da parte aérea apresentou comportamento parecido com a característica anterior, as plantas provenientes de mudas produzidas com o substrato padrão proporcionaram o maior acúmulo de massa seca da parte aérea (Tabela 3). No desdobramento de recipientes dentro de cada turno de rega foram observados efeitos significativos de recipientes em todos os turnos de rega aplicados.

Na Figura 4, são apresentados os comportamentos dos cafeeiros no que diz respeito à massa seca da parte aérea em função do recipiente utilizado na produção das mudas e do turno de rega utilizado. Novamente, as plantas provenientes de mudas produzidas no recipiente saquinho de polietileno se destacaram das demais. As plantas provenientes de mudas produzidas em tubetes de $50 \mathrm{~mL}$ obtiveram desenvolvimento inferior. 
Tabela 3 - Valores médios ${ }^{1}$ de número de nós nos ramos plagiotrópicos, área foliar e massa seca da parte aérea (MSPA) de cafeeiros aos 120 dias após o transplante para vasos em casa de vegetação, em função de diferentes substratos. UFLA, Lavras, MG, 2006.

\begin{tabular}{cccc}
\hline Substrato & $\begin{array}{c}\mathrm{N}^{\mathrm{o}} \text { de nós nos ramos } \\
\text { plagiotrópicos }\end{array}$ & Área Foliar $\left(\mathrm{cm}^{2}\right)$ & MSPA $(\mathrm{g})$ \\
\hline Alternativo & $15,39 \mathrm{~b}$ & $2210,44 \mathrm{~b}$ & $35,28 \mathrm{~b}$ \\
Comercial & $15,49 \mathrm{~b}$ & $2268,40 \mathrm{~b}$ & $36,03 \mathrm{~b}$ \\
Padrão & $17,77 \mathrm{a}$ & $2462,53 \mathrm{a}$ & $40,56 \mathrm{a}$ \\
\hline
\end{tabular}

${ }^{1}$ Médias seguidas pela mesma letra minúscula na vertical, não diferem entre si, pelo teste de Scott-Knott, ao nível de 5\% de probabilidade.

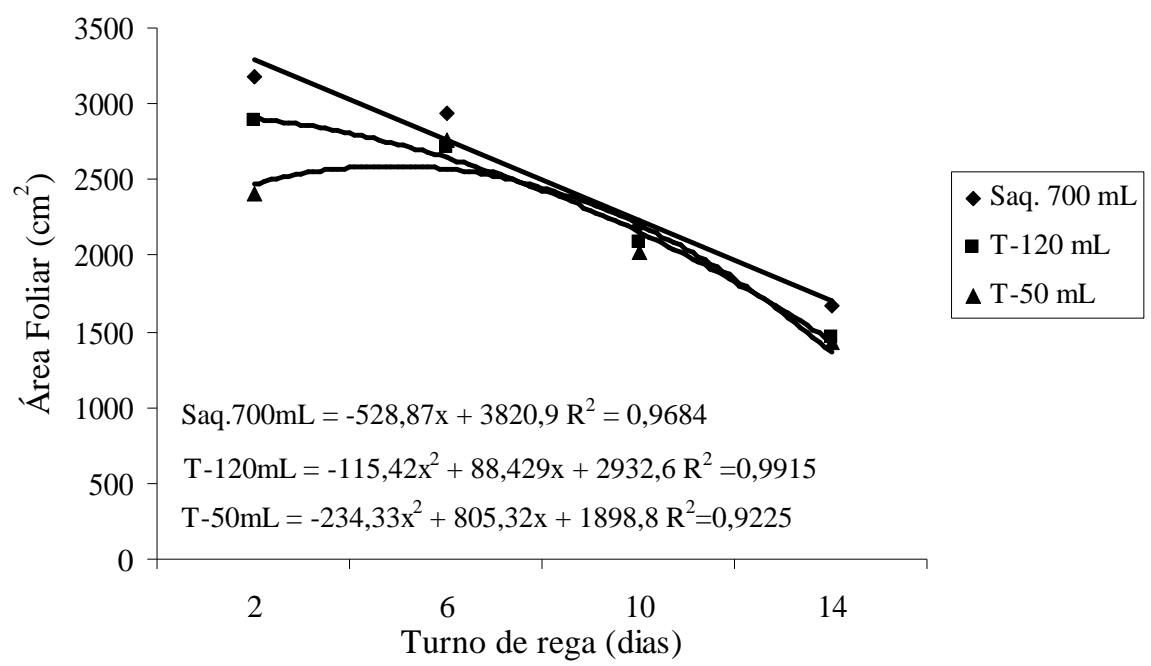

Figura 2 - Área foliar de cafeeiros aos 120 dias após o plantio em função do recipiente utilizado na produção de mudas e do turno de rega após o plantio. UFLA, Lavras, 2006.

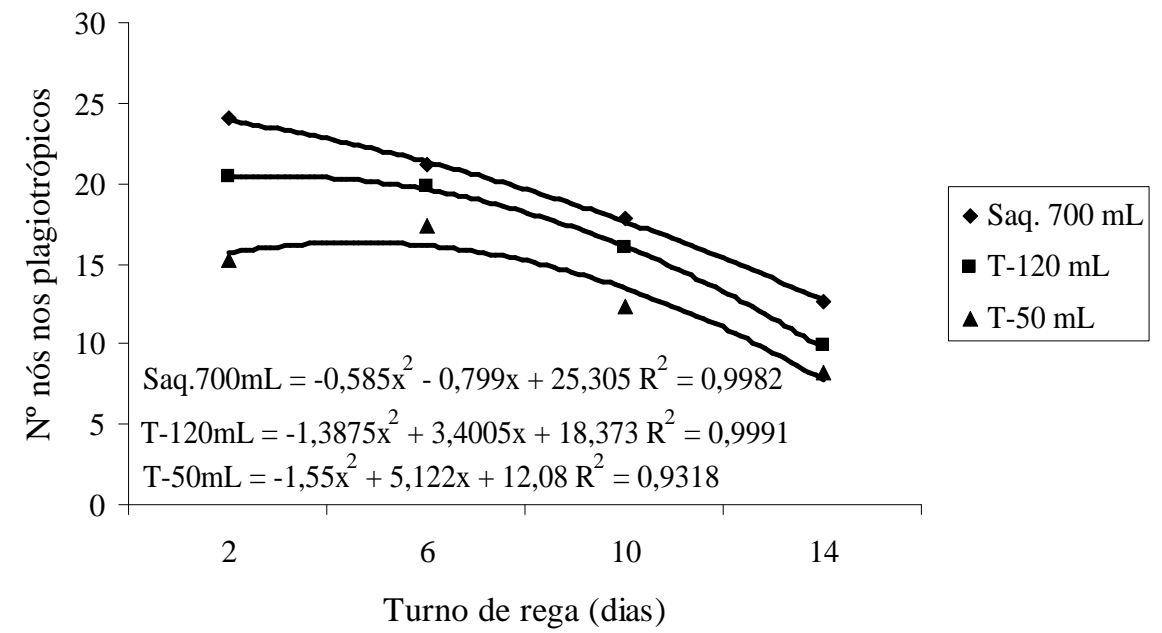

Figura 3 - Número de nós nos ramos plagiotrópicos de cafeeiros aos 120 dias após o plantio em função do recipiente utilizado na produção de mudas e do turno de rega após o plantio. UFLA, Lavras, 2006. 


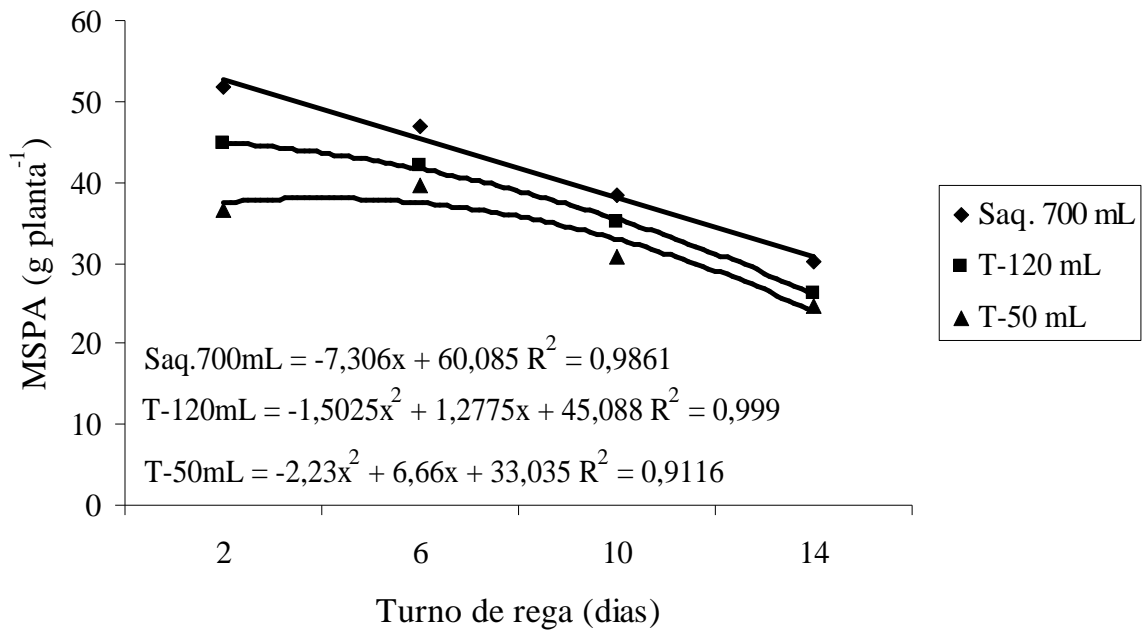

Figura 4 - Massa seca da parte aérea de cafeeiros aos 120 dias após o plantio em função do recipiente utilizado na produção de mudas e do turno de rega após o plantio. UFLA, Lavras, 2006.

A massa seca do sistema radicular apresentou efeitos significativos para as interações recipientes $\mathrm{X}$ turno de rega e substratos $\mathrm{X}$ turno de rega. Observa-se que houve efeitos significativos nos turnos de rega dois, seis e dez dias e que, em todos estes intervalos, as mudas oriundas de saquinhos de polietileno de $700 \mathrm{~mL}$ se destacaram novamente, sendo que apenas no turno de rega de quatorze dias, as médias foram semelhantes às alcançadas pelas mudas provenientes do tubete de $120 \mathrm{~mL}$ (Figura 5). Com relação à interação substrato $\mathrm{X}$ turno de rega, as plantas provenientes de mudas produzidas com substrato alternativo e comercial se comportaram de maneira semelhante, sendo inferiores às plantas oriundas de mudas produzidas em substrato padrão (Figura 6).

A relação entre a massa seca do sistema radicular e da parte aérea apresentou efeitos significativos para a interação recipientes X substratos e para a interação recipientes X turno de rega. Os efeitos de recipientes dentro de cada substrato revelaram interações significativas apenas para plantas provenientes de mudas produzidas, utilizando substrato alternativo e substrato padrão (Figura 7). Já, os efeitos de substratos dentro de cada recipiente, revelaram interações significativas apenas nas mudas produzidas em tubetes de $120 \mathrm{~mL}$ e saquinho de polietileno de $700 \mathrm{~mL}$ (Tabela 4).

Observa-se que as mudas produzidas em tubetes de $50 \mathrm{~mL}$ alcançaram menores médias de relação massa seca do sistema radicular/massa seca da parte aérea, resultado contrário ao obtido no experimento anterior, de produção de mudas. As mudas produzidas nos saquinhos de polietileno $(700 \mathrm{~mL})$, que na fase de viveiro alcançaram menores médias desta característica, nos vasos, recuperaram-se e obtiveram médias superiores, sendo igualadas às dos tubetes de $120 \mathrm{~mL}$ quando se utilizou substrato padrão. Quanto à interação recipiente $X$ turno de rega, foram detectados efeitos significativos nos turnos de rega de seis, dez e quatorze dias e as mudas produzidas nos recipientes saquinho de polietileno e tubete de $120 \mathrm{~mL}$ foram superiores às mudas produzidas nos tubetes de 50 $\mathrm{mL}$, à exceção do turno de rega de 14 dias, onde as mudas de tubete de $120 \mathrm{~mL}$ foram superiores às produzidas em saquinho e tubete de $50 \mathrm{~mL}$. A relação entre a massa seca do sistema radicular e da parte aérea é uma característica muito utilizada como indicativo de qualidade de mudas, porém, Johnson \& Cline (1991), relatam que não deve ser avaliada isoladamente, pois, essa relação pode mudar facilmente, em função do tamanho da muda e isso dificulta comparações e interpretações dos dados.

Percebe-se uma tendência em todos os resultados desse experimento para uma superioridade das plantas provenientes de mudas produzidas em saquinhos de polietileno e com substrato padrão. Os efeitos do recipiente são semelhantes aos encontrados por vários pesquisadores que verificaram o melhor desempenho inicial de plantas oriundas de recipientes de maiores capacidades volumétricas e que a restrição radicular, em recipientes de volume reduzido, durante o período de produção de mudas pode reduzir o desenvolvimento não só durante a fase de viveiro, mas também após o transplante no campo (Aguiar \& Melo, 1974; Reis et al., 1989; Matiello et al., 2000; Samôr et al., 2002). Quanto aos efeitos dos substratos, o substrato padrão, que proporcionou mudas com menores médias no experimento de produção de mudas (Vallone, 2006), sobressaiu em relação 
aos demais, durante o experimento de vasos e proporcionou plantas com médias superiores. Esse resultado é semelhante aos obtidos por Aguiar \& Melo (1974) que, testando vários recipientes na produção de mudas de eucalipto, utilizaram um substrato constituído por terra de subsolo e esterco bovino, isto é, muito parecido com o substrato padrão utilizado neste experimento e, durante a fase de viveiro, o recipiente que proporcionou menores médias foi o torrão paulista. Entretanto, quando os tratamentos foram levados para o campo, as mudas oriundas desse recipiente obtiveram os maiores incrementos em altura. Os autores atribuíram este resultado ao fato do sistema radicular das mudas no torrão paulista ter explorado na fase de viveiro um volume limitado de solo que apresentava características compactadas, dada a natureza do substrato e do recipiente. Após o transplante, as raízes, ao se libertarem do recipiente, encontraram um ambiente mais adequado ao seu desenvolvimento do que aquele em que estavam condicionadas. Além disso, essas raízes, desenvolvidas inicialmente em um meio mais drástico e estressante, revelaram uma grande capacidade de explorar o solo, após o transplante no campo. Outro aspecto é que o substrato padrão é muito parecido com o solo em que as mudas foram transplantadas nos vasos, o que favorece a adaptação das raízes.

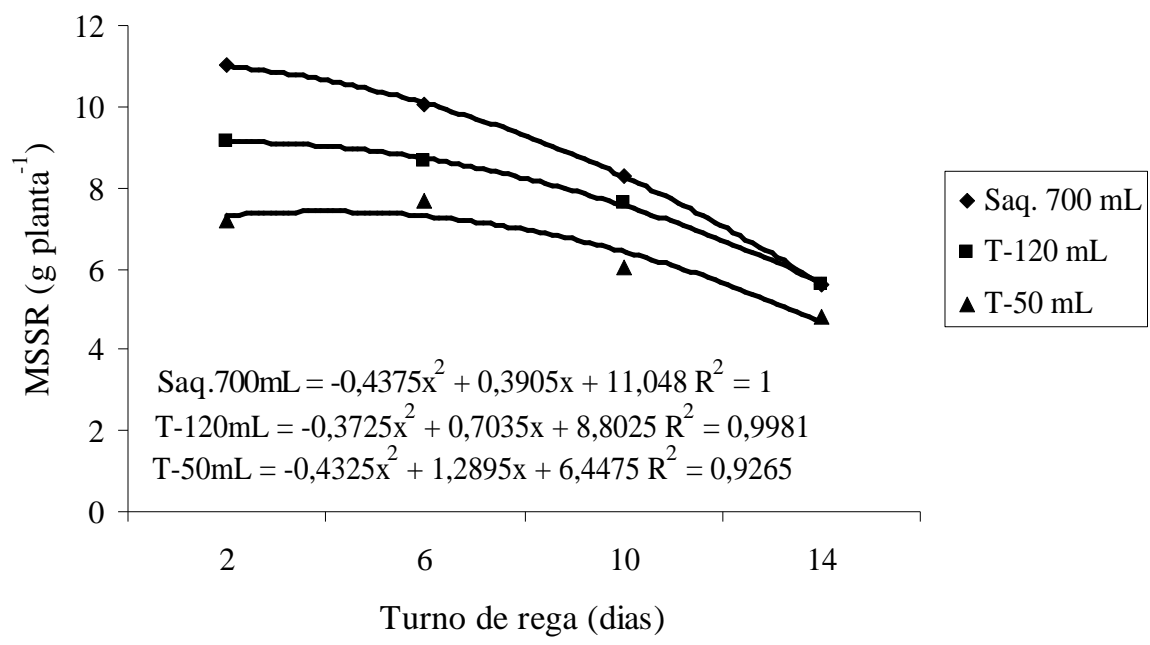

Figura 5 - Massa seca do sistema radicular de cafeeiros aos 120 dias após o plantio em função do recipiente utilizado na produção de mudas e do turno de rega após o plantio. UFLA, Lavras, 2006.

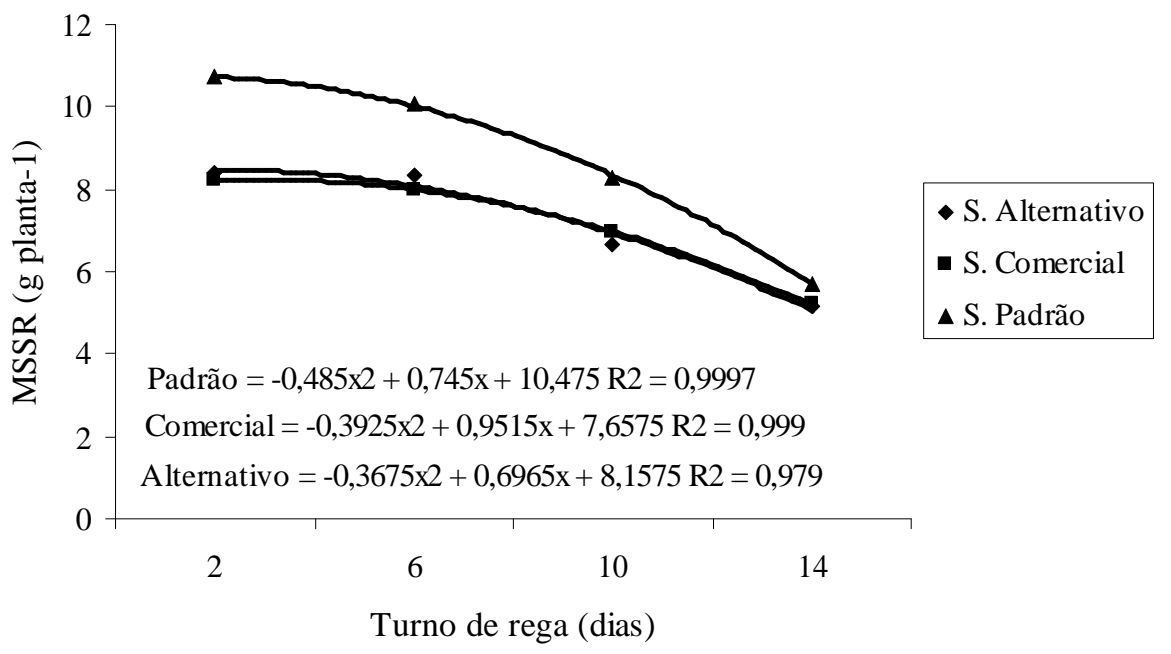

Figura 6-Massa seca do sistema radicular de cafeeiros, aos 120 dias após o plantio, em função do substrato utilizado na produção de mudas e do turno de rega após o plantio. UFLA, Lavras, 2006. 


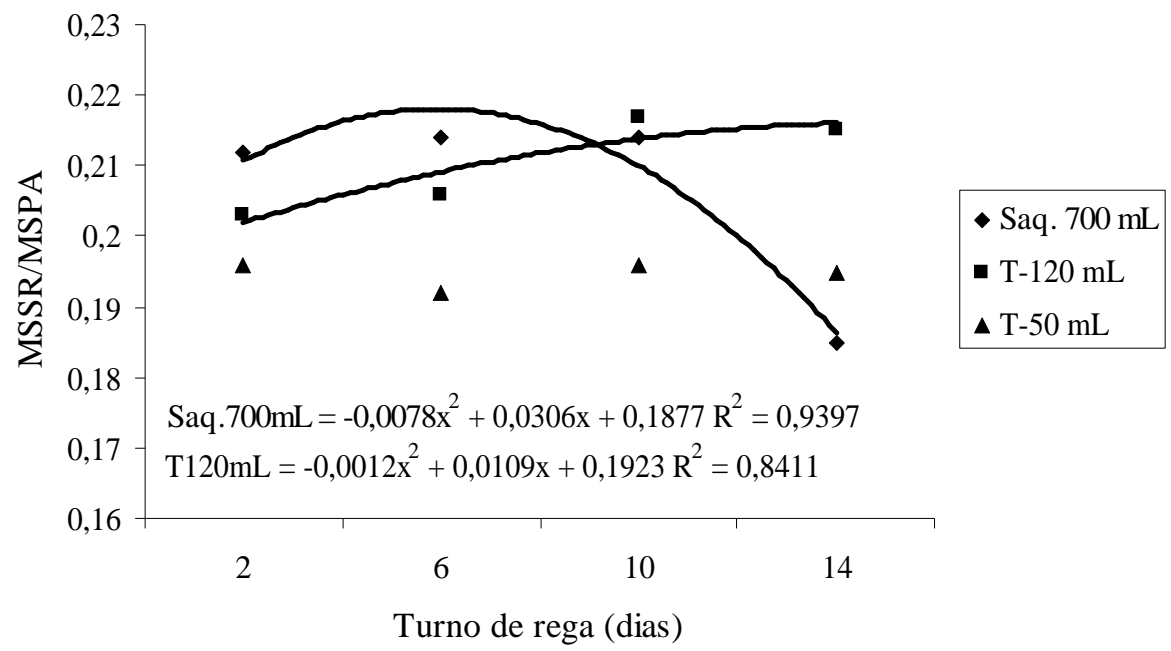

Figura 7 - Relação entre massa seca do sistema radicular e massa seca da parte aérea de cafeeiros, aos 120 dias após o plantio, em função do recipiente utilizado na produção de mudas e do turno de rega após o plantio. UFLA, Lavras, 2006.

Tabela 4 - Valores médios ${ }^{1}$ da relação entre massa seca do sistema radicular e massa seca da parte aérea de cafeeiros 120 dias após o transplante, em função de diferentes recipientes ${ }^{2}$ e substratos. UFLA, Lavras, MG, 2006.

\begin{tabular}{cccc}
\hline Recipiente & \multicolumn{3}{c}{ Substratos } \\
\cline { 2 - 4 } & Alternativo & Comercial & Padrão \\
\hline Tubete $50 \mathrm{~mL}$ & 8,187 b A & 8,128 a A & 8,076 b A \\
Tubete $120 \mathrm{~mL}$ & 8,114 b B & 8,228 a B & 8,976 a A \\
Saquinho $-700 \mathrm{~mL}$ & 8,593 a B & 8,346 a B & 9,187 a A \\
\hline
\end{tabular}

${ }^{1}$ Médias seguidas pela mesma letra minúscula na vertical e maiúscula na horizontal, não diferem entre si, pelo teste de Scott-Knott, ao nível de $5 \%$ de probabilidade.

\section{CONCLUSÕES}

Os resultados obtidos permitem concluir que, após 120 dias do transplante das mudas para vasos em casa de vegetação com diferentes níveis de estresse hídrico, as plantas, provenientes de mudas produzidas em saquinhos de polietileno de $700 \mathrm{~mL}$, preenchidos com substrato padrão, apresentaram maior desenvolvimento que as demais. Entretanto, apresentam maior sensibilidade ao estresse hídrico.

\section{REFERÊNCIAS BIBLIOGRÁFICAS}

AGUIAR, I.B. de; MELLO, A.A. Influência do recipiente na produção de mudas e no desenvolvimento inicial após o plantio no campo, de Eucalyptus grandis Hill ex Maiden e Eucalyptus saligna Smith. IPEF, Piracicaba, v.8, p.19-40, 1974.

BANZATTO, D.A.; KRONKA, S.N. Experimentação agrícola. 3.ed. Jaboticabal: Funep, 1995. 247p.
FALCO, L.; GUIMARÃES, R.J.; CARVALHO, G.R.; GERVASIO, E.S.; MANGINI, D. Avaliação da resistência ao déficit hídrico de mudas de cafeeiro produzidas por diferentes métodos: saquinho, tubetes e raiz nua. In: CONGRESSO BRASILEIRO DE PESQUISAS

CAFEEIRAS, 23., 1997, Manhuaçu. Anais... Rio de Janeiro: MAPA/PROCAFÉ, 1997. p.178-179.

FERREIRA, D.F. Análises estatísticas por meio do Sisvar para Windows versão 4.0. In: REUNIÃO ANUAL DA REGIÃO BRASILEIRA DA SOCIEDADE

INTERNACIOANL DE BIOMETRIA, 45., 2000, São Carlos. Anais... São Carlos: UFSCar, 2000. p.255-258.

FREITAS, A.S. de; BARROSO, D.G.; CARNEIRO, J.G. de A.; PENCHEL, R.M.; LAMÔNICA, K.R.; FERREIRA, D. de A. Desempenho radicular de mudas de eucalipto produzidas em diferentes recipientes e substratos. Revista Árvore, Viçosa, v.29, n.6, p.853-861, nov./dez. 2005. 
GUIMARÃES, P.T.G.; GARCIA, A.W.R.; ALVAREZ, V.H.; PREZOTTI, L.C.; VIANA, A.S.; MIGUEL, A.E.; MALAVOLTA, E.; CORRÊA, J.B.; LOPES, A.S.; NOGUEIRA, F.D.; MONTEIRO, A.V.C.; OLIVEIRA, J.A. de. Cafeeiro. In: RIBEIRO, A.C.; GUIMARÃES, P.T.G.; ALVARES, V.H. (Eds.). Recomendações para o uso de corretivos e fertilizantes em Minas

Gerais: $5^{\text {a }}$ aproximação. Viçosa, MG: UFV, 1999. p.289-302.

\section{GUIMARÃES, R.J.; MENDES, A.N.G. Produção de} mudas de cafeeiro. Lavras: UFLA/FAEPE, 1998. 60p.

JOHNSON, J.D.; CLINE, M.L. Seedling quality of southern pines. In: DUREYA, M.L.; DOUGHERTY, P.M. (Eds.). Forest regeneration manual. Doudrecht: Kluwer Academic, 1991. p.143-162.

MATIELLO, J.B.; BARROS, U.V.; BARBOSA, C.M. Modos de plantio de mudas de café produzidas em tubetes plásticos, em comparação com mudas de sacolas, na Zona da Mata de Minas. In: CONGRESSO BRASILEIRO DE PESQUISAS CAFEEIRAS, 26., 2000, Marília. Anais... Rio de Janeiro: IBC/GERCA, 2000. p.2123.
MELO, W.J. de; MELO, G.M.P. de; BERTIPAGLIA, L.M.A.; MELO, V.P. de. Experimentação sob condições controladas. Jaboticabal: Funep, 1998. 82p.

REIS, G.G.; REIS, M.G.F.; MAESTRI, M.; XAVIER, A.; OLIVEIRA, L.M. Crescimento de Eucayiptus camaldulensis, E. grandis e E. cloeziana sob diferentes níveis de restrição radicular. Revista Árvore, Viçosa, v.13, n.1, p.1-18, 1989.

SAMÔR, O.J.M.; CARNEIRO, J.G. de A.; BARROSO, D.G.; LELES, P.S. dos S. Qualidade de mudas de angico e sesbânia, produzidas em diferentes recipientes e substratos. Revista Árvore, Viçosa, v.26, n.2, p.209-215, abr./jun. 2002.

SCHIMIDT-VOGT, H. Morpho-physiological quality of forest tree seedlings: the present international status of research. In: SIMPÓSIO INTERNACIONAL: MÉTODOS DE PRODUÇÃO E CONTROLE DE QUALIDADE DE SEMENTES E MUDAS FLORESTAIS, 1984, Curitiba. Anais... Curitiba: FUPEF, 1984. p.366-378.

VALLONE, H.S. Recipientes e substratos na produção de mudas e no desenvolvimento inicial de cafeeiros (Coffea arabica L.). Lavras: UFLA, 2006. 89p. 